\title{
Perceptional Barriers in Hepatitis C Therapy: A Cross-Sectional Assessment of the Patients from Khyber Pakhtunkhwa Pakistan
}

\author{
Muhammad Daud*, Saima Mehboob, Bushra Gul and Waheed Ullah \\ Department of Gastroenterology/Hepatology, Hayatabad Medical Complex, \\ Peshawar, Pakistan \\ *Corresponding Author: Muhammad Daud, Department of Gastroenterology/ \\ Hepatology, Hayatabad Medical Complex, Peshawar, Pakistan.
}

Received: May 17, 2021

Published: June 11, 2021

(C) All rights are reserved by Muhammad

Daud., et al.

\begin{abstract}
Objective: To determine the perception of local resident patients regarding chronic hepatitis C infection using the BIPQ (brief illness perception questionnaire).

Materials and Methods: This Observational, cross-sectional study was performed in two hospitals, selected from two districts of KPK (Khyber Pakhtunkhwa), a tertiary care hospital from District Peshawar, and a secondary care hospital from District Charsadda. Patients with chronic Hepatitis C (HCV RNA positive through PCR analysis), of age $\geq 18$ years, mentally sound, and lacking any major comorbidities were included in the study. The study duration was 1 year lasting from January 2018 to December 2018 . Patients were recruited through non-probability Convenience sampling and face-to-face interviews for duration of 10 - 15 minutes were conducted in the outpatient departments of each hospital.

Descriptive statistics were used to describe the demographic characteristics of the study participants and the scoring of BIPQ. Kolmogorov-Smirnov test was used for determining the normality of the data. Inferential statistics (Mann Whitney U test and Kruskal-Wallis tests) were used for comparative analysis of study variables. Spearman's rho correlation was used to check the association between the BIPQ item scales and overall score. Binary logistic regression was applied to identify the predictable variables responsible for overall threat or benign condition of the patients. Results with $\mathrm{P} \leq 0.05$ were considered statistically significant. Microsoft Excel 2016, and IBM SPSS V.21.0 were used for data analysis and interpretation.

Results: A total of 550 patients were approached for participation but only 525 patients showed consented for inclusion in the study (95.45\% response rate). Mean age of the participants was 43.94 (11.90) years. Majority were females with a frequency of 301 $(57.4 \%)$ and out of these, stay at home wives were 294 (56\%). Most of the patients were of lower middle age i.e. 31 - 45 years. Illiteracy was high among the participants 426 (81.1\%). Patients who were daily wages job workers (DWJWs) were 127 (24.2\%), and those who had previously experienced some kind of failed HCV therapy were 197 (37.5\%) (Table 1).

BIPQ results showed that Patients had the highest Concern score with a Mean (SD) of 8.09 (2.09); followed by Treatment control, 7.92 (2.13); and lowest on the Coherence item scale, 2.92 (1.85). According to the instructions, the overall sum score of BIPQ was calculated, which was found to be 43.35 (13.15) Mean (SD), and it also showed an internal consistency of $\alpha=0.859$ (Table 2).
\end{abstract}

Citation: Muhammad Daud., et al. "Perceptional Barriers in Hepatitis C Therapy: A Cross-Sectional Assessment of the Patients from Khyber Pakhtunkhwa Pakistan". Acta Scientific Gastrointestinal Disorders 4.7 (2021): 32-39. 
BIPQ results showed that Patients had the highest Concern score with a Mean (SD) of 8.09 (2.09); followed by Treatment control, 7.92 (2.13); and lowest on the Coherence item scale, 2.92 (1.85). According to the instructions, the overall sum score of BIPQ was calculated, which was found to be 43.35 (13.15) Mean (SD), and it also showed an internal consistency of $\alpha=0.859$ (Table 2).

Females showed higher emotional representation and lower Coherence than males with $\mathrm{p} \leq 0.05$. Daily wages job workers (DWJWs) showed higher concern $(\mathrm{p} \leq 0.05)$. Treatment-experienced patients scored less on treatment control $(\mathrm{p}=0.029)$ and high on disease chronicity ( $\mathrm{p} \leq 0.01$ ) when compared with newly diagnosed HCV patients (Table 3). BIPQ Overall score showed significant strong and positive correlation with Consequences $(r=0.822, p \leq 0.01)$, identity $(r=0.816, p \leq 0.01)$, and strong negative correlation with treatment control $(r=-0.715, p \leq 0.01)$ and Your-control $r=-0.700, p \leq 0.01$ (Table 4). On the basis of Overall score (Total score = 80), patients were divided into the final two categories for research purpose. Patients who scored 0 - 40 were labeled "Benign" (i.e. having good perception, less threat), and those with a score ranging from 41 - 80 were labeled "Threat" (i.e. Bad perception, higher threat). Binary logistic regression of these two categories with independent study variables indicated that only failed previous treatment experience of the patients had a significant effect on the overall patients' perceived threat of the disease, $\chi^{2}(1)=1.587, p<0.05$, (95\%CI: 1.096, 2.296).

Regarding the most probable source of infection most patients $(79.23 \%)$ were unable to identify any transmission risk factor for Hepatitis C. Some of the participants (8.5\%) indicated that unsterilized dental practices as the cause of their infection. Some pointed out mental stress, pollution, and spiritual reasons as a cause of infection (Figure 1).

Conclusion: Patients lacked information and understanding of the causality and transmission of risk factors of HCV infection and they showed high concerns for their lives and families. Previously failed HCV treatment experiences altered the patients' perceptions negatively as they were doubtful of the success of modern more effective drugs available.

Keywords: Perception; Chronic Hepatitis C; Infection; BIPQ

\section{Introduction}

Hepatitis $\mathrm{C}$ virus (HCV) has been recognized as a major cause of chronic liver diseases throughout the world [1]. Hepatitis $\mathrm{C}$ is a blood-borne infection, transmitted through HCV contaminated blood and blood products, body piercings, illicit drug use, needlestick injuries, unhygienic and unsterilized surgical procedures, hemodialysis, and organ transplants. Hepatitis $C$ viral infection can lead to hepatocellular carcinoma, liver cirrhosis, and ultimately hepatic failure in severe cases [2,3].

World Health Organization (WHO) reports that 3.3\% of the world population is infected with $\mathrm{HCV}$, and each year more than 350,000 people are dying from Hepatitis C related liver diseases [4,5]. The first HCV infection reported in Pakistan was in 1992 and since then, the disease burden has left all the major developed countries like USA, Europe and Japan behind in HCV prevalence. Currently, Pakistan ranks second amongst the highest HCV prevalent countries in the world, next to Egypt with a prevalence of $4.7 \%$ [6-8].
It's a fact that most of the HCV carrying patients are unaware of their disease and do not follow proper therapy to promote behavioral changes and adopt precautionary lifestyle [9]. Patients usually self-evaluate the risks of developing a specific illness at some point in their lives, create their own personal beliefs, and prepare themselves for the consequences they have to face $[10,11]$. These personal beliefs and perceptions determine the cognitive, behavioral and emotional reactions of patients that how they handle their disease, therapy, and ultimate therapeutic outcomes [12]. Cognitive perceptions refer to the identity, causality, chronicity, and control of the disease, while fear, anger, anxiety, and psychological distress refer to the emotional perceptions $[13,14]$. These self-manifested perceptions of the patients greatly influence not only their adaptive behavior but also make it a difficult task for health care professionals to deal with them on the individual level [15-17].

The concept of illness perception has gained importance in the recent years, and they are considered to be amongst the most important psychological variables accountable for predicting the be- 
havior of patients in chronic diseases $[12,18]$. It is known for the Pakistani population that, "when they are diagnosed with Hepatitis C, they think they will die" [19]. Despite this concern, which shall indicate the eagerness of the patients to opt for the therapy and adapt the precautionary lifestyle, new HCV cases are being reported in the hospitals of Pakistan on a daily basis.

So, in this study, the HCV patients of Khyber Pakhtunkhwa (KPK) Pakistan are evaluated for the first time to determine the barriers in their perception and behavior about Hepatitis $\mathrm{C}$ infection, a gift that keeps on giving.

\section{Methodology}

Study design and settings

Observational, cross-sectional study design was adopted for the study, and two hospitals were selected from two districts of KPK. A tertiary care hospital from District Peshawar, and a secondary care hospital from District Charsadda. Hepatitis $\mathrm{C}$ patients (tested through serum HCV RNA PCR analysis), of age $\geq 18$ years, mentally sound, and lacking any major comorbidities were included in the study. The study duration lasted from January 2018 to December 2018. Convenience sampling technique was followed, and face-toface interviews with a duration of 10 - 15 minutes were conducted with the patients visiting the outpatient Hepatitis $C$ clinics of each hospital.

\section{Ethical approval}

The study was approved by the Bio-Ethical Committee of Quaidi-Azam University Islamabad (Protocol No. BEC-FBS-QAU-104). Ethical approval was taken from committees of both the corresponding hospitals. Patients were also briefed about the study and informed consent was obtained prior to their involvement in the study.

\section{Study tool}

A paper-based structured questionnaire was used for data collection. It consisted of two parts; the first part was comprised of information about the history and socio-demographic characteristics of the patients, and the second part consisted of pre-validated "Brief Illness Perception Questionnaire (BIPQ)". The term "illness" was replaced by "Hepatitis C" for study purpose. BIPQ has nine items; eight of these items represent different cognitive beliefs of the patients. Five of these items represent negative perception outcomes (higher the score, higher the threat), and include consequences (how much patients' lives are affected), timeline (chronicity of the disease), identity (association of symptoms with the disease), concern, and emotional representation (anger, negative thinking, fear etc). Other three items represent positive perception outcomes (higher the score lower the threat level) and include personal control (patients' self-will and determination), treatment control, and coherence (understanding of the disease).

Each item is scored on 11 points Likert scale ranging from 0 to 10. A higher score represents a greater endorsement of the patient about that particular item. The Ninth item is an open-ended question about the patient's belief of major factors responsible for their Hepatitis C infection [20].

\section{Statistical analysis}

Descriptive statistics were used to describe the demographic characteristics of the study participants and the scoring of BIPQ. Kolmogorov-Smirnov test was used for determining the normality of the data. Inferential statistics (Mann Whitney U test and KruskalWallis tests) were used for comparative analysis of study variables. Spearman's rho correlation was used to check the association between the BIPQ item scales and overall score. Binary logistic regression was applied to identify the predictable variables responsible for overall threat or benign condition of the patients. Results with $\mathrm{P} \leq 0.05$ were considered statistically significant. Microsoft Excel 2016, and IBM SPSS V.21.0 were used for data analysis and interpretation.

\section{Results}

\section{Demographic characteristics}

A total of 550 patients were approached for the study, and only 525 patients showed consent for participation (95.45\% response rate). Mean age of the participants was 43.94 (11.90) years. Majority of the participants were females with a frequency of 301 (57.4\%), and out of these, stay at home wives were 294 (56\%). Most of the patients were of lower middle age i.e., 31-45 years. Illiteracy was high among the participants, and those with no education were 426 (81.1\%). Patients who were daily wages job workers (DWJWs) were 127 (24.2\%), and those who had previously experienced some kind of failed HCV therapy were 197 (37.5\%). Further details are given in table 1. 


\begin{tabular}{|c|c|c|c|}
\hline Characteristic & Categories & $\begin{array}{c}\text { Frequency } \\
\mathbf{N}=525\end{array}$ & Percentage \\
\hline \multirow[t]{2}{*}{ Sex } & Male & 224 & 42.7 \\
\hline & Female & 301 & 57.3 \\
\hline \multirow{4}{*}{ Age (years) } & Young (18 - 30) & 74 & 14.1 \\
\hline & lower middle (31 - 45) & 232 & 44.2 \\
\hline & $\begin{array}{l}\text { higher middle } \\
(46-60)\end{array}$ & 171 & 32.6 \\
\hline & Old $(>61)$ & 48 & 9.1 \\
\hline \multirow[t]{3}{*}{ Marital Status } & Married & 510 & 97.2 \\
\hline & Unmarried & 11 & 2.1 \\
\hline & Widow (er) & 4 & 0.7 \\
\hline \multirow{6}{*}{ Qualification } & Illiterate & 426 & 81.1 \\
\hline & Primary & 45 & 8.6 \\
\hline & Islamic & 8 & 1.5 \\
\hline & High School & 28 & 5.3 \\
\hline & College & 12 & 2.3 \\
\hline & University & 6 & 1.1 \\
\hline \multirow{5}{*}{ Job Status } & Jobless & 30 & 5.7 \\
\hline & Stay at Home Wife & 294 & 56 \\
\hline & Daily Wages & 127 & 24.2 \\
\hline & Self-Employed & 61 & 11.6 \\
\hline & Government & 13 & 2.5 \\
\hline \multirow{5}{*}{$\begin{array}{l}\text { Income Per } \\
\text { Month (PKR)* }\end{array}$} & $\leq 10,000$ & 89 & 17 \\
\hline & $11,000-20,000$ & 405 & 77.1 \\
\hline & $21,000-30,000$ & 24 & 4.6 \\
\hline & $31,000-40,000$ & 5 & 1 \\
\hline & $41,000-50,000$ & 2 & 0.4 \\
\hline \multirow{2}{*}{$\begin{array}{l}\text { Previous } \\
\text { Therapy }\end{array}$} & Yes & 328 & 62.5 \\
\hline & No & 197 & 37.5 \\
\hline \multirow{7}{*}{$\begin{array}{l}\text { Reason for HCV } \\
\text { Diagnosis }\end{array}$} & Precaution & 11 & 2.1 \\
\hline & Pre travel & 5 & 1 \\
\hline & Pre-blood donation & 5 & 1 \\
\hline & Pre dental extraction & 26 & 5 \\
\hline & Pregnancy & 26 & 5 \\
\hline & Pre-Op & 25 & 4.8 \\
\hline & Typical Symptoms & 427 & 81.3 \\
\hline
\end{tabular}

Table 1: Participants demographic details.

\section{BIPQ results}

Patients showed highest Concern score with a Mean (SD) of 8.09 (2.09); followed by Treatment control, 7.92 (2.13); and lowest on the Coherence item scale, 2.92 (1.85). According to the instructions, the overall sum score of BIPQ was calculated, which was found to be 43.35 (13.15) Mean (SD), and it also showed a good internal consistency of $\alpha=0.859$. Details are given in table 2 .

\begin{tabular}{|l|c|}
\hline \multicolumn{1}{|c|}{ Study Item } & Mean (SD) (N = 525) \\
\hline Consequences $^{\mathrm{n}}$ & $5.07(2.67)$ \\
\hline Timeline $^{\mathrm{n}}$ & $5.44(2.41)$ \\
\hline Personal Control $^{\mathrm{p}}$ & $5.50(2.64)$ \\
\hline Treatment Control $^{\mathrm{p}}$ & $7.92(2.13)$ \\
\hline Identity $^{\mathrm{n}}$ & $4.97(2.36)$ \\
\hline Concern $^{\mathrm{n}}$ & $8.08(2.09)$ \\
\hline Coherence $^{\mathrm{p}}$ & $2.92(1.86)$ \\
\hline Emotional Representation $^{\mathrm{n}}$ & $6.13(2.27)$ \\
\hline Overall Score $^{\mathrm{n}}$ & $43.35(13.15)$ \\
\hline
\end{tabular}

Table 2: Descriptive statistics of BIPQ item scales. Results SD means Standard Deviation.

$\mathrm{n}$ : Marked questionnaire items indicate higher score as a negative perception.

$\mathrm{p}$ : Marked questionnaire items indicate higher score as a positive perception.

Females showed higher emotional representation and lower Coherence than males with $\mathrm{p} \leq 0.05$. Daily wages job workers (DWJWs) showed higher concern than HCV patients of any other occupation ( $\mathrm{p} \leq 0.05)$. Treatment-experienced patients scored less on treatment control $(p=0.029)$ and high on disease chronicity ( $p$ $\leq 0.01$ ) when compared with newly diagnosed HCV patients. Further details are given in table 3.

BIPQ Overall score showed significant strong and positive correlation with Consequences $(r=0.822, p \leq 0.01)$, identity $(r=0.816$, $\mathrm{p} \leq 0.01)$, and strong negative correlation with treatment control ( $\mathrm{r}$ $=-0.715, \mathrm{p} \leq 0.01)$, and Your-control $(\mathrm{r}=-0.700, \mathrm{p} \leq 0.01)$. Details are given in table 4.

On the basis of Overall score (Total score $=80$ ), patients were divided into the final two categories for research purpose. Patients 


\begin{tabular}{|c|c|c|c|c|c|c|c|c|}
\hline Characteristic & Consequences & Timeline & $\begin{array}{c}\text { Your } \\
\text { control }\end{array}$ & $\begin{array}{c}\text { Treatment } \\
\text { control }\end{array}$ & Identity & Concern & Coherence & $\begin{array}{c}\text { Emotional } \\
\text { Representation }\end{array}$ \\
\hline Sex ${ }^{a}$ & 0.755 & 0.156 & 0.051 & 0.229 & 0.871 & 0.108 & $0.006^{*}$ & $0.040^{*}$ \\
\hline $\operatorname{Age}^{\mathrm{b}}(43.94 \pm 11.90)$ & $0.026^{*}$ & 0.014 & 0.335 & 0.383 & 0.235 & $0.005^{*}$ & 0.714 & $0.041^{*}$ \\
\hline Qualification ${ }^{\mathrm{b}}$ & 0.264 & 0.375 & $0.005^{*}$ & 0.081 & 0.624 & $0.007^{*}$ & 0.064 & 0.111 \\
\hline Job Status ${ }^{\mathrm{a}}$ & 0.140 & 0.246 & $0.010^{*}$ & 0.244 & 0.316 & $0.046^{*}$ & 0.126 & $0.008^{*}$ \\
\hline $\begin{array}{l}\text { Income Per Month } \\
(\mathrm{PKR})^{\mathrm{b}}\end{array}$ & 0.355 & 0.145 & $0.035^{*}$ & 0.280 & 0.240 & 0.135 & 0.591 & 0.260 \\
\hline Previous Therapy ${ }^{\mathrm{a}}$ & 0.600 & $0.000^{* *}$ & 0.060 & 0.029 & 0.106 & 0.101 & 0.950 & 0.397 \\
\hline $\begin{array}{l}\text { Reason for HCV } \\
\text { Diagnosis }^{\mathrm{b}}\end{array}$ & 0.437 & 0.084 & 0.408 & 0.176 & 0.442 & $0.002^{*}$ & 0.183 & 0.102 \\
\hline $\begin{array}{l}\text { Psychological Con- } \\
\text { dition }^{\mathrm{a}}\end{array}$ & $0.000^{* *}$ & $0.000^{* *}$ & $0.000^{* *}$ & $0.000^{* *}$ & $0.000^{* *}$ & $0.000^{* *}$ & $0.010^{* *}$ & $0.000^{* *}$ \\
\hline
\end{tabular}

Table 3: Comparative analysis of BIPQ items among the demographic variables of the study participants.

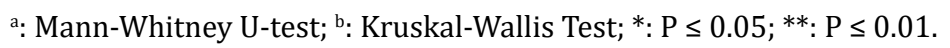

\begin{tabular}{|l|c|c|c|c|c|c|c|c|c|}
\hline & Consequences & Timeline & $\begin{array}{c}\text { Your } \\
\text { Control }\end{array}$ & $\begin{array}{c}\text { Treatment } \\
\text { Control }\end{array}$ & Identity & Concern & Coherence & $\begin{array}{c}\text { Emotional } \\
\text { Representation }\end{array}$ & $\begin{array}{c}\text { Overall } \\
\text { Score }\end{array}$ \\
\hline Consequences & 1.000 & & & & & & & & \\
\hline Timeline & $.658^{* *}$ & 1.000 & & & & & & & \\
\hline Your Control & $-.442^{* *}$ & $-.479^{* *}$ & 1.000 & & & & & & \\
\hline Treatment Control & $-.478^{* *}$ & $-.510^{* *}$ & $.588^{* *}$ & 1.000 & & & & & \\
\hline Identity & $.756^{* *}$ & $.606^{* *}$ & $-.401^{* *}$ & $-.508^{* *}$ & 1.000 & & & & \\
\hline Concern & $.550^{* *}$ & $.467^{* *}$ & $-.479^{* *}$ & $-.366^{* *}$ & $.561^{* *}$ & 1.000 & & & \\
\hline Coherence & .003 & .006 & .055 & .062 & -.042 & .074 & 1.000 & & \\
\hline $\begin{array}{l}\text { Emotional Repre- } \\
\text { sentation }\end{array}$ & $.626^{* *}$ & $.556^{* *}$ & $-.382^{* *}$ & $-.441^{* *}$ & $.639^{* *}$ & $.540^{* *}$ & -.061 & 1.000 & \\
\hline \begin{tabular}{l} 
Overall Score \\
\hline$* *$ Correlation is \\
significant at the \\
0.01 level (2-tailed).
\end{tabular} & $.822^{* *}$ & $.779^{* *}$ & $-.700^{* *}$ & $-.715^{* *}$ & $.816^{* *}$ & $.698^{* *}$ & $-.133^{* *}$ & $.760^{* *}$ & 1.000 \\
\hline
\end{tabular}

Table 4: Spearman's rho correlation results between the overall score and BIPQ item scales.

who scored 0-40 were labeled "Benign" (i.e. having good perception, less threat), and those with a score ranging from 41-80 were labeled "Threat" (i.e. Bad perception, higher threat). Binary logistic regression of these two categories with independent study vari- ables indicated that only failed previous treatment experience of the patients had a significant effect on the overall patients' perceived threat of the disease, $\chi^{2}(1)=1.587, \mathrm{p}<0.05$, (95\%CI: 1.096, 2.296). 
In response to answering what the most probable cause of HCV infection? Most of the patients (79.23\%) were unable to identify even a single transmission risk factor for Hepatitis $\mathrm{C}$ infection. Some of the study cohort (8.5\%) indicated that unsterilized dental practices were the cause of their acquired HCV infection. Some pointed out that mental stress, pollution and spiritual reasons were the main cause of them being infected with HCV. Details are given in figure 1.

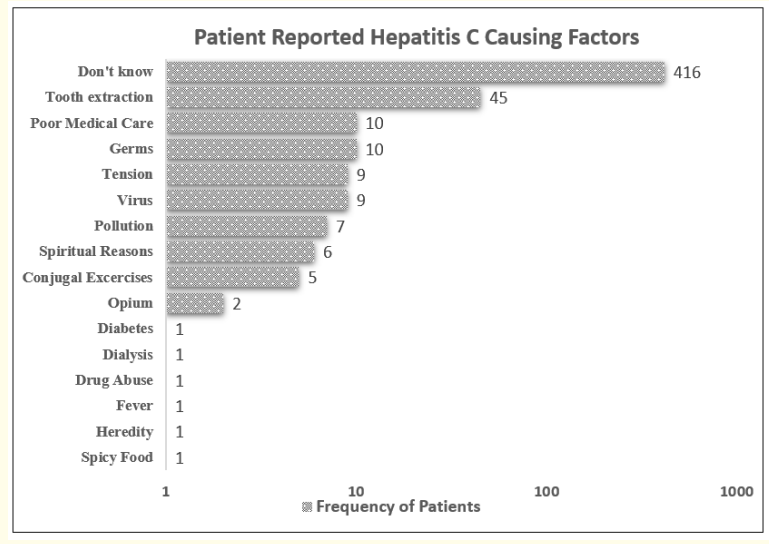

Figure 1: Frequency of patient reported hepatitis C Causing factors.

\section{Discussion}

Hepatitis $\mathrm{C}$ is perceived differently by patients coming from different aspects of life and working environments. Social and working environments lead to the development of particular mindsets and beliefs conforming the patients' perception about a particular disease. Our study highlights that the majority of patients were lacking knowledge about the causative agents for hepatitis $\mathrm{C}$ infection. However, some of the study participants indicated that unhygienic, non-sterile dental practices were the main HCV transmission risk factors. These findings are supportive of the previously performed studies [21-24].

Our study reveals that being diagnosed with HCV infection was quite an unfortunate surprise for the patients. Patients of older age were particularly afraid of bitter life consequences, probably because they were afraid of being shunned off from their social circles and loss of support from friends and family members. This is also evident in a study of USA patients [25].

Hepatitis $\mathrm{C}$ needs prompt attention and therapy to be eradicated off the body. Lack of awareness and understanding render the affected concerned for their lives. Illiterate patients and daily wages job workers showed a higher concern for HCV infection than other patients. The concern for HCV infection was also found in the patients attending the Hepatology clinics in France [26]. Similarly, patients with daily wages jobs showed higher emotional disturbance than patients of other occupations. As, deteriorating health was rendering them unable to do the physical work, which was the only economic support for them and their families. The employees of Japan upon diagnosis with infectious disease faced similar problems and worries [27]. However, the emotional disturbance that HCV brings to the patients was more prominent in female patients when compared to their male counterparts. This is quite a different finding from the notion that being social enables female patients apt to deal with their emotional distress in a better way than males [28]. A reason might be due to lack of education, stay at home environments, and little exposure to the outside community.

Chronic HCV patients who had experienced failed HCV treatments in the past believed in high chronicity of the disease. Moreover, they were not hopeful about the efficacy of new therapeutic regimes for $\mathrm{HCV}$ infection. It may be due to lack of symptomatic relief, unbearable side effects, and poor success rates of previous therapies they received for HCV infection [29]. Failure of therapy to achieve these goals averts the patients from adhering to their treatment regimens, which results in sub-optimal therapeutic outcomes [30]. So, easy to take medicines with lesser or no side effects, and with high cure rates are the ideal candidates for these kind of patients. It will help in bringing their hopes up and ensure treatment adherence. The work of Lauren., et al. in Boston, studying motivating factors associated with the therapy of hepatitis $\mathrm{C}$ infection is a better example for understanding these factors [31]. Nevertheless, our study participants believed in the efficacy of new therapies available in the hospitals, which is, after all, a good sign of their trust in health care settings and health care professionals for the future.

\section{Conclusion}

Patients were lacking information and understanding of the causality and transmission risk factors of HCV infection. They were 
worried about their lives and families. Extensive counseling and education are needed for the general public, especially the illiterate and female community about HCV infection. A little extra time for them by the health care professionals will improve their morale, bring psychological relief, and improve the patient determination to take responsibility for their own health. Government shall take necessary measures to implement standard infection control procedures in local dental practitioners to stop the transmission of HCV in the community.

Previously failed HCV treatment experiences altered the patients' perceptions and they were doubtful of the success of modern medicines. Patients need special counseling sessions by the health care professionals about the risk factors, proper medication use, and side effects. It will develop their trust in the health care system, ensure their compliance and adherence to the therapy. Awareness about transmission risk factors will help in the HCV transmission, as a precautionary lifestyle will help in prevention of the disease spread. All these factors will ultimately help in achieving the World Health Organization's sustainable development goals of eradicating HCV infection once and for all.

\section{Limitations of the Study}

The study was conducted in government hospitals, which is most probably visited by patients of lower socioeconomic status in Pakistan. So, we were unable to have a large population of patients with higher education and high socioeconomic status to know their perception. Secondly, it was a cross-sectional study, and we were unable to observe their perception at the end of therapy.

In future, quality of life assessment of these patients can give us a better understanding of their psychological, physical and social improvement, not only with the therapy but also with the counseling and education sessions of the health care professionals.

\section{Acknowledgments}

We really appreciate the help of hospital staff of Lady Reading Hospital, Medical Teaching Institute Peshawar, and District Headquarter Hospital Charsadda for their kind support in accessing the patients and conducting interviews in Hepatitis Clinics.

\section{Bibliography}

1. Shepard CW., et al. "Global epidemiology of hepatitis $C$ virus infection". The Lancet Infectious Diseases 5.9 (2005): 558-567.
2. Khan S., et al. "Molecular epidemiology of HCV among health care workers of Khyber Pakhtunkhwa". Virology Journal 8.1 (2011): 1 .

3. Sylvestre DL., et al. "Co-occurring hepatitis C, substance use, and psychiatric illness: treatment issues and developing integrated models of care". Journal of Urban Health 81.4 (2004): 719-734.

4. Mohamed AA., et al. "Hepatitis C virus: A global view 7.26 (2015): 2676.

5. Mohd Hanafiah K., et al. "Global epidemiology of hepatitis C virus infection: New estimates of age-specific antibody to HCV seroprevalence". Hepatology 57.4 (2013): 1333-1342.

6. Nabi S and Mubarik A. "Hepatitis $\mathrm{C}$ as a cause of chronic liver disease in northern Pakistan (1992).

7. Higuchi M., et al. "Epidemiology and clinical aspects on hepatitis C". Japanese Journal of Infectious Diseases 55.3 (2002): 6977.

8. Sievert W., et al. "A systematic review of hepatitis $\mathrm{C}$ virus epidemiology in Asia, Australia and Egypt". Liver International 31.2 (2011): 61-80.

9. Smith BD., et al. "Centers for Disease Control and Prevention initiatives to prevent hepatitis $\mathrm{C}$ virus infection: a selective update". Clinical Infectious Diseases 55.1 (2012): S49-S53.

10. Kaptein AA., et al. "Using the common-sense model to predict risk perception and disease-related worry in individuals at increased risk for venous thrombosis". Health Psychology 26.6 (2007): 807.

11. Petrie KJ and Weinman J. "Perceptions of health and illness". Current research and applications: Taylor and Francis (1997).

12. Karatas T., et al. "Factor Structure and Psychometric Properties of the Brief Illness Perception Questionnaire in Turkish Cancer Patients". Asia-Pacific Journal of Oncology Nursing 4.1 (2017): 77-83.

13. Leventhal H., et al. "The Common-Sense Model of Self-Regulation (CSM): A dynamic framework for understanding illness self-management". 39.6 (2016): 935-946. 
14. Broadbent E., et al. "A systematic review and meta-analysis of the Brief Illness Perception Questionnaire". 30.11 (2012): 1361-1385.

15. Voigt A., et al. "Association of glycaemia with perceived threat of illness in patients with type 2 diabetes". 9.6 (2015): 426431.

16. Leventhal H., et al. "Illness Representations and Coping With Health Threats (Handbook of Psychology and Health) (1984).

17. Min J., et al. "Transcultural Adaptation and Validation of the Korean Version of the Brief Illness Perception Questionnaire for Patients with Pulmonary Tuberculosis". Journal of Global Infectious Diseases 9.3 (2017): 113-116.

18. Løchting I., et al. "Evaluation of the brief illness perception questionnaire in sub-acute and chronic low back pain patients: data quality, reliability and validity". 2 (2013): 122.

19. Frontieres MS. "When they are diagnosed with Hepatitis C, patients think they will die Spain". Medecin Sans Frontiere (2016).

20. Broadbent E., et al. "The brief illness perception questionnaire". 60.6 (2006): 631-637.

21. Bari A., et al. "Risk factors for hepatitis $\mathrm{C}$ virus infection in male adults in Rawalpindi-Islamabad, Pakistan". Tropical Medicine and International Health 6.9 (2001): 732-738.

22. Krishanani MK., et al. "Educational intervention among barbers about liver cancer-inducing viruses: a pilot study from a developing country". Journal of Cancer Education 25.4 (2010): 632-636.

23. Butt AK., et al. "Dentistry as a possible route of hepatitis $\mathrm{C}$ transmission in Pakistan". International Dental Journal 53.3 (2003): 141-144.

24. Amon JJ. "Hepatitis in drug users: time for attention, time for action". The Lancet 378.9791 (2011): 543.

25. Blasiole JA., et al. "Mental and physical symptoms associated with lower social support for patients with hepatitis C". 12.29 (2006): 4665.
26. Castera L., et al. "Psychological impact of chronic hepatitis C: comparison with other stressful life events and chronic diseases". 12.10 (2006): 1545.

27. Oka T., et al. "Employment-related difficulties and distressed living condition in patients with hepatitis B virus: A qualitative and quantitative study". 17.1 (2017): 568.

28. Bianco T., et al. "Gender differences in the quality of life of patients with liver cirrhosis related to hepatitis $\mathrm{C}$ after liver transplantation". 36.3-4 (2013): 231-236.

29. Bian D-D., et al. "Current treatment status and barriers for patients with chronic HCV infection in mainland China: A national multicenter cross-sectional survey in 56 hospitals". 96.34 (2017).

30. Larrey D and Ripault M-P. “Pageaux G-PJPp, adherence. Patient adherence issues in the treatment of hepatitis C". 8 (2014): 763.

31. Fusfeld L., et al. "Assessment of motivating factors associated with the initiation and completion of treatment for chronic hepatitis C virus (HCV) infection". BMC Infectious Diseases 13.1 (2013): 234.

\section{Volume 4 Issue 7 July 2021 \\ (C) All rights are reserved by Muhammad Daud., et al.}

\section{.}

